\title{
Developmental Differences in Acute Nigrostriatal and Mesocorticolimbic System Response to Haloperidol
}

Martin H. Teicher, M.D., Ph.D., Natacha I. Barber, B.A., Harris A. Gelbard, M.D., Ph.D., Amelia L. Gallitano, B.A., Alexander Campbell, M.Phil., Elda Marsh, B.S., and Ross J. Baldessarini, M.D.

Dose-dependent effects of haloperidol $(2.66 \mathrm{nmol} / \mathrm{kg}$ to $79.8 \mathrm{mmol} / \mathrm{kg}, \mathrm{IP}$ ) on levels of dopamine, homovanillic acid (HVA) and dihydroxyphenylacetic acid (DOPAC) were assessed in the corpus striatum, nucleus accumbens, and medial prefrontal cortex (PFCTX) of 18-, 30-, and 110-day-old rats. Eighteen-day-old rats were $35 \%$ and $63 \%$ more sensitive than adults to the effects of haloperidol on striatal and accumbens turnover and had steeper dose-response curves. The dose-response function in the PFCTX was similar to striatum at 18 days, but became shallower and nonsigmoidal with age. Maximally effective doses of haloperidol produced, at all ages, a comparable percent rise in DOPAC levels in all regions. With maturation, the percent rise in HVA progressively outstripped DOPAC response in nucleus accumbens and striatum. Overall, prominent developmental differences emerged in these regions in their sensitivity and response to haloperidol, which are consistent with previously reported differences in behavioral sensitivity.

[Neuropsychopharmacology 9:147-156, 1993]
KEY WORDS: Haloperidol; Dopamine; Corpus striatum; Nucleus accumbens; Prefrontal cortex; Development

Haloperidol is a prototypical neuroleptic agent that has value throughout the lifespan in the treatment of psychotic disorders and behavioral agitation (e.g., Baldessarini, 1985). Some clinical data are available to guide dosing with this or other antipsychotic agents in adults (Baldessarini et al. 1989), but much less is known about optimal dosing in childhood or adolescence (Teicher and Glod 1989). A rational initial approach is to ascertain whether there are important developmental differences in the behavior and neuropharmacologic effects

\footnotetext{
From the Department of Psychiatry and Neuroscience Program, Harvard Medical School and Developmental Psychopharmacology Laboratory and Neuropharmacology Laboratory, Laboratories for Psychiatric Research, Mailman Research Center, McLean Hospital, Belmont, Massachusetts

Address correspondence to: Dr. Martin H. Teicher, McLean Hospital, 115 Mill Street, Belmont, MA 02178.

Received September 18, 1992; revised March 5, 1993 and May 19, 1993; accepted May 19, 1993.
}

of this representative agent on laboratory animals. Studies by Campbell and Baldessarini and colleagues (Campbell and Baldessarini 1981; Campbell et al. 1988) found that developing rats are much more sensitive to the acute behavioral effects of neuroleptics than adults. The $\mathrm{ED}_{50}$ for haloperidol-induced catalepsy, sedation (ptosis), and bradykinesia, respectively, was 16-, 60-, and 75-fold lower in 1-month-old rats than in 18-monthold rats (Campbell and Baldessarini 1981). These differences were not accounted for by drug disposition factors. First, similar age differences occurred in response to a chemically dissimilar neuroleptic, perphenazine (Campbell et al. 1988). Even more significantly, parallel age differences in dose response to haloperidol and perphenazine were obtained following direct intracerebroventricular administration, which bypassed the effects of peripheral metabolism, distribution, and blood-brain barrier penetration (Campbell et al. 1988). These observations strongly suggest that there are important pharmacodynamic differencesacross age in sensitivity to neuroleptic agents. Supporting these findings 
are receptor-binding studies that reveal prominent changes in the density of $D_{1}$ and $D_{2}$ dopamine (DA) receptors in the striatum of developing rats (Gelbard et al. 1989). $D_{1}$ and $D_{2}$ receptor density at puberty (40 days) was, respectively, 2.3- and 4.0-fold greater than in early adulthood (120 days). A similar ontogenetic pattern has also been observed in man (Seeman et al. 1987). With such marked developmental changes in DA receptor density, it would be surprising if there were no differences in pharmacodynamic response.

In the present study we sought to ascertain whether there are major developmental differences in acute regional response of ascending forebrain DA systems to systemically administered haloperidol. Tissue concentrations of DA, homovanillic acid (HVA), and dihydroxyphenylacetic acid (DOPAC) were quantified in the corpus striatum, nucleus accumbens, and medial prefrontal cortex (PFCTX) following acute challenge with a range of doses of haloperidol, to provide data on age-related changes in nigrostriatal and mesocorticolimbic DA system sensitivity and responsiveness to this drug.

\section{MATERIALS AND METHOD}

\section{Animals}

Sprague-Dawley rats were obtained from Charles River Laboratories. Eighteen-day-old preweaning rats and 30day-old peripubertal rats of both sexes were raised in our colony from litters born to multiparous mothers shipped on the day following delivery. Young adult male rats ( 110 days old) were purchased from the same source and adapted to the colony for at least 1 week prior to study. Animals were maintained on a conventional 0700 to 1900 hour light-dark cycle. Food and water were available ad libitum. Eighteen day olds resided with their natural litters (10 to 12 pups). Thirty-day-old animals were weaned on day 22 and were housed in hanging wire group cages with same-sex littermates. Adult rats also were group housed (4 per cage) in similar cages. Altogether, 215 animals were used as subjects in this study.

\section{Drug Administration and Dosing}

Haloperidol (donated by McNeil Laboratories) was dissolved in one or two drops of 1 mol lactic acid, diluted in distilled water, and adjusted to a $\mathrm{pH}$ of between 5.0 and 5.5 , for administration by intra-peritoneal (IP) injection in volumes of $0.5 \mathrm{ml} / \mathrm{kg}$, at doses ranging from $1 \mu \mathrm{g}$ to $30 \mathrm{mg}$ per kilogram of body weight $(2.66 \mathrm{nmol}$ $\mathrm{kg}$ to $79.8 \mathrm{mmol} / \mathrm{kg}$ ). The maximum dose of haloperidol studied at each age was selected to be sublethal, but to produce maximal or declining levels of metabolites in striatal tissue and to mimic or exceed the full range of dosages used in clinical practice. For 18-day-old animals, the maximum dose of haloperidol was limited to $3 \mathrm{mg} / \mathrm{kg}(7.98 \mathrm{mmol} / \mathrm{kg})$, for 30 -day-olds it was 10 $\mathrm{mg} / \mathrm{kg}(2.66 \mathrm{mmol} / \mathrm{kg})$ and for 100-day-olds it was 30 $\mathrm{mg} / \mathrm{kg}(79.8 \mathrm{mmol} / \mathrm{kg})$. Vehicle controls received injections of $0.01 \mathrm{mmol}$ lactic acid adjusted to a $\mathrm{pH}$ of between 5.0 and 5.5. Injections occurred between 1000 and 1400 hours to minimize circadian variation in response noted previously (Campbell and Baldessarini 1982). Following drug administration, 18-day-old rats were returned to their home cage, whereas 30 -day and 110-day-old subjects were placed with their usual cagemates in plastic group cages. The doses and number of subjects per cell are summarized in Table 1.

\section{Regional Brain Dissection}

Animals were sacrificed by decapitation 2 hours after drug administration. The brain was removed, sprayed with ice-cold isotonic saline, and cut into 1.5 - to $2.0-\mathrm{mm}$

Table 1. Number of Tissue Samples Analyzed by Age, Dosage, and Brain Region

\begin{tabular}{|c|c|c|c|c|c|c|c|c|c|c|c|}
\hline & \multicolumn{11}{|c|}{ Haloperidol Doses (mg/kg) } \\
\hline & $\mathbf{0}$ & 0.001 & 0.01 & 0.02 & 0.06 & 0.1 & 0.3 & 1 & 3 & 10 & 30 \\
\hline \multicolumn{12}{|l|}{ 18-day-olds } \\
\hline Striatum & 16 & & 6 & 10 & 12 & 6 & 12 & 6 & 6 & & \\
\hline Accumbens & 16 & & 6 & 10 & 8 & 6 & 10 & 6 & 6 & & \\
\hline PFCTX & 8 & 2 & 4 & & & 5 & & 4 & 5 & & \\
\hline \multicolumn{12}{|l|}{ 30-day-olds } \\
\hline Striatum & 19 & & & 11 & 12 & 6 & 8 & 6 & 5 & 4 & \\
\hline Accumbens & 19 & & & 5 & 12 & 6 & 10 & 6 & 6 & 4 & \\
\hline PFCTX & 8 & 2 & 2 & & & 6 & & 5 & 6 & 4 & \\
\hline \multicolumn{12}{|l|}{ 110-day-olds } \\
\hline Striatum & 17 & 2 & 2 & & & 6 & 12 & 5 & 6 & 4 & 10 \\
\hline Accumbens & 18 & 2 & 2 & & & 6 & 10 & 6 & 7 & 4 & 7 \\
\hline PFCTX & 8 & 2 & 2 & & & 6 & & 6 & 5 & 4 & \\
\hline
\end{tabular}


coronal sections on a micrometer-mounted cutting pedestal (Stoelting tissue chopper). Sequential forebrain slabs were placed on an iced Petri dish, striatum and nucleus accumbens were removed by freehand dissection, and PFCTX was removed for a selected subset of brains (Teicher et al. 1986, 1991). Specimens were weighed and stored at $-70^{\circ} \mathrm{C}$ until analysis. The number of individual sections assayed from each region is indicated in Table 1.

\section{Regional Brain Analysis}

Tissue concentrations of DA, HVA, and DOPAC were determined by high-pressure liquid chromatography with

EC) as described in detail elsewhere (Baldessarini et al. 1990). Individual samples were homogenized in $0.1 \mathrm{~N}$ perchloric acid solution (PCA) containing $0.1 \mathrm{mmol}$ $\mathrm{Na}_{2}$ ethylenediaminetetraacetic acid (EDTA), $0.4 \mathrm{mmol}$ sodium metabisulfite and 3,4-dihydroxybenzylamine (DHBA) as internal standard. After a 5-minute centrifugation $(9,000 \times g)$, the supernatant, in $100 \mu$ l samples, was injected into a Rainin Rabbit HP Solvent Delivery System $(1.0 \mathrm{ml} / \mathrm{min})$, separated on a Rainin C18 reversephase $5-\mu \mathrm{m}$ column $(4.6 \mathrm{~mm} \times 25 \mathrm{~cm})$, and detected amperometrically using a Bioanalytical Systems (Model LC-4B).

For striatum and accumbens, DOPAC and HVA were analyzed by direct injection of the supernatant, and DA was analyzed after alumina extraction (Baldessarini et al. 1990). In PFCTX, DOPAC, HVA, and DA were analyzed in a single run by direct injection of the sample supernatant. The mobile phase for this assay consisted of $0.1 \mathrm{~mol}$ sodium acetate, $0.2 \mathrm{mmol}$ $\mathrm{Na}_{2}$ EDTA, $0.5 \mathrm{mmol}$ 1-heptane sulfonic acid, $12 \%$ (vols) methanol, adjusted to $\mathrm{pH} 5.0$ with glacial acetic acid (HPLC grade, Fisher Scientific), and detected at $+0.75 \mathrm{~V}$ using a glassy carbon analytical electrode and an $\mathrm{Ag} / \mathrm{AgCl}$ referenceelectrode. Aberrant HPLC results (more than 3 standard deviations from the mean) were eliminated prior to data analysis, as they most likely reflected errors in dissection, storage, or analysis.

\section{Statistical Analysis}

Dose-response data were quantified using a Macintosh version of ALLFIT (DeLean et al. 1978) written by M. Teicher. Neurochemical data were fit to a four-parameter logistic model with minimum and maximum response levels set equal to effects obtained at zero dose and at maximally effective dose. Computerized curve fitting yielded values $( \pm S E M)$ for slope and $E D_{50}$. Age differences were ascertained by simultaneous constrained curve fitting, which determines an F-ratio for the significance in degradation in goodness-of-fit, when the program was required to calculate a parameter forced to be equal between age groups (DeLean et al. 1978). For biphasic dose-response functions, ALLFIT was used to model response to the ascending aspect of the curve, which included the peak and subsequent plateau phase (within $15 \%$ of peak).

Several comparisons are expressed as percent change from the baseline (vehicle control) condition. Whenever this conversion was made, the SEM was calculated using a statistical procedure that takes into account both the variability in the treatment group and the variability in the vehicle-treated control condition (McLean and Welch 1971).

Differences between groups in basal and maximal stimulated levels of DA metabolites were determined using analysis of variance procedures for unequal sample sizes (Keppel 1973). Planned comparisons between specific ages and conditions were evaluated using Student's $t$-tests. Data are reported as means \pm SEM unless stated otherwise. Nonsignificant differences are indicated as "NS."

\section{RESULTS}

\section{Striatum}

Developmental Differences in Basal Metabolite Concentrations and Metabolite-to-Transmitter Ratios. Dopamine levels in striatum were only $48 \% \pm 5 \%$ of adult levels at 18 days $(p<.0001)$, and $75 \% \pm 7 \%$ at 30 days $(p<.0001)$. There were also significant developmental differences in basal levels of HVA and DOPAC (Table 2). Levels of HVA were slightly greater at 18 and 30 days than in adults $(p<.02)$, whereas DOPAC levels were substantially lower at 18 days than at 30 days $(p<.0001)$ or adulthood $(p<.0001)$. Thus, the basal ratio of HVA to DOPAC changed markedly with age $(F=51.5, p<$ $.0001)$. At 18 days, HVA levels were $87 \% \pm 4 \%$ as high as DOPAC levels. At 30 days, basal HVA levels had fallen to $57 \% \pm 2 \%$ of DOPAC levels, and at 110 days they were only $46 \% \pm 2 \%$. These alterations in levels of HVA and DOPAC suggest major developmental differences in the way DA is metabolized. Metaboliteto-transmitter ratios ([HVA + DOPAC]/DA) were calculated as an estimate of overall DA turnover. This ratio changed substantially during development $(F=$ 23.6, $p<.0001)$. Dopamine turnover was $58 \% \pm 9 \%$ greater at 18 days and $25 \% \pm 6 \%$ greater at 30 days than in early adulthood $(p<.0002)$.

Age Differences in Sensitivity to the Effects of Haloperidol on Striatal DA Metabolism. There were strong developmental differences in sensitivity to haloperidol based on the combined metabolite response $(F=11.8$, $p<.001)$ or metabolite/transmitter ratios $(F=23.8$, $p<.0001$; Fig. 1). As seen in Table 2, the dose of haloperidol necessary to produce a half-maximal DA metabolite response in striatal tissue was much lower dur- 
Table 2. Dopamine Metabolite Response to Haloperidol in Corpus Striatum

\begin{tabular}{|c|c|c|c|c|c|c|c|}
\hline Measure & $\begin{array}{c}\text { Age } \\
\text { (days) }\end{array}$ & $\begin{array}{l}\text { Basal Level } \\
\text { (ng/mg) }\end{array}$ & $\begin{array}{c}\text { Dose-Response } \\
\text { Slope }\end{array}$ & $\begin{array}{c}\text { Drug Potency } \\
\text { ED }_{50}\end{array}$ & $\begin{array}{c}\text { Maximal } \\
\text { Level } \\
\text { (ng/mg) }\end{array}$ & $\begin{array}{c}\text { Maximum \% } \\
\text { Change }\end{array}$ & $\begin{array}{c}\text { Maximally } \\
\text { Effective } \\
\text { Dose (ED }\left(\text { D }_{\text {max }}\right)\end{array}$ \\
\hline $\mathrm{A}$ & $\begin{array}{r}18 \\
30 \\
110\end{array}$ & $\begin{array}{r}5.365 \pm 0.230 \\
8.392 \pm 0.404 \\
11.193 \pm 0.877\end{array}$ & & & & & \\
\hline HVA & $\begin{array}{r}18 \\
30 \\
110\end{array}$ & $\begin{array}{l}0.901 \pm 0.037 \\
0.959 \pm 0.050 \\
0.787 \pm 0.025\end{array}$ & $\begin{array}{l}2.28 \pm 0.84 \\
3.74 \pm 1.28 \\
0.96 \pm 0.48\end{array}$ & $\begin{array}{l}0.050 \pm 0.009 \\
0.086 \pm 0.007 \\
0.121 \pm 0.059\end{array}$ & $\begin{array}{l}2.48 \pm 0.17 \\
3.39 \pm 0.10 \\
3.94 \pm 0.02\end{array}$ & $\begin{array}{l}275.8 \pm 26.3 \\
353.1 \pm 36.3 \\
501.4 \pm 26.9\end{array}$ & $\begin{array}{l}0.1 \\
1.0 \\
1.0\end{array}$ \\
\hline DOPAC & $\begin{array}{r}18 \\
30 \\
110\end{array}$ & $\begin{array}{l}1.032 \pm 0.062 \\
1.579 \pm 0.072 \\
1.710 \pm 0.099\end{array}$ & $\begin{array}{l}1.76 \pm 0.58 \\
2.24 \pm 0.85 \\
1.83 \pm 0.86\end{array}$ & $\begin{array}{l}0.069 \pm 0.012 \\
0.111 \pm 0.019 \\
0.224 \pm 0.061\end{array}$ & $\begin{array}{l}2.73 \pm 0.20 \\
4.46 \pm 0.04 \\
4.79 \pm 0.97\end{array}$ & $\begin{array}{l}264.9 \pm 33.4 \\
282.3 \pm 23.1 \\
280.4 \pm 63.0\end{array}$ & $\begin{array}{l}1.0 \\
1.0 \\
3.0\end{array}$ \\
\hline $\begin{array}{l}\text { DOPAC } \\
+ \text { HVA }\end{array}$ & $\begin{array}{r}18 \\
30 \\
110\end{array}$ & $\begin{array}{l}1.977 \pm 0.098 \\
2.528 \pm 0.112 \\
2.695 \pm 0.148\end{array}$ & $\begin{array}{l}2.27 \pm 0.64 \\
3.48 \pm 1.33 \\
1.42 \pm 0.23\end{array}$ & $\begin{array}{l}0.049 \pm 0.007 \\
0.093 \pm 0.009 \\
0.156 \pm 0.018\end{array}$ & $\begin{array}{l}5.12 \pm 0.34 \\
7.82 \pm 0.09 \\
8.04 \pm 0.07\end{array}$ & $\begin{array}{l}259.1 \pm 28.9 \\
309.4 \pm 27.7 \\
298.4 \pm 34.0\end{array}$ & $\begin{array}{c}1.0 \\
1.0 \\
1.0-3.0\end{array}$ \\
\hline $\begin{array}{l}\text { (DOPAC } \\
\quad+\text { HVA } / \mathrm{DA}\end{array}$ & $\begin{array}{r}18 \\
30 \\
110\end{array}$ & $\begin{array}{l}0.354 \pm 0.018 \\
0.281 \pm 0.011 \\
0.224 \pm 0.007\end{array}$ & $\begin{array}{l}4.26 \pm 3.02 \\
1.27 \pm 0.39 \\
0.66 \pm 0.13\end{array}$ & $\begin{array}{l}0.057 \pm 0.007 \\
0.184 \pm 0.050 \\
0.089 \pm 0.028\end{array}$ & $\begin{array}{l}0.961 \pm 0.103 \\
1.063 \pm 0.113 \\
0.768 \pm 0.077\end{array}$ & $\begin{array}{l}271.4 \pm 36.5 \\
378.1 \pm 47.1 \\
342.2 \pm 37.4\end{array}$ & $\begin{array}{l}1.0 \\
3.0 \\
3.0\end{array}$ \\
\hline
\end{tabular}

ing early development and rose progressively from the preweaning period to young adulthood.

\section{Nucleus Accumbens}

Developmental Differences in Basal Metabolite Concentrations and Metabolite-to-Transmitter Ratios. In the nucleus accumbens there was no significant effect of age on basal levels of DA or HVA. Levels of DOPAC, however, nearly doubled after 18 days. As in striatum, the ratio of HVA to DOPAC changed considerably with age $(F=25.7, p<.0001)$. At 18 days, HVA levels were $67 \% \pm 6 \%$ of DOPAC levels, but were only $36 \%$ to $38 \%$ in 30- and 110-day-old animals. Basal turnover rates at
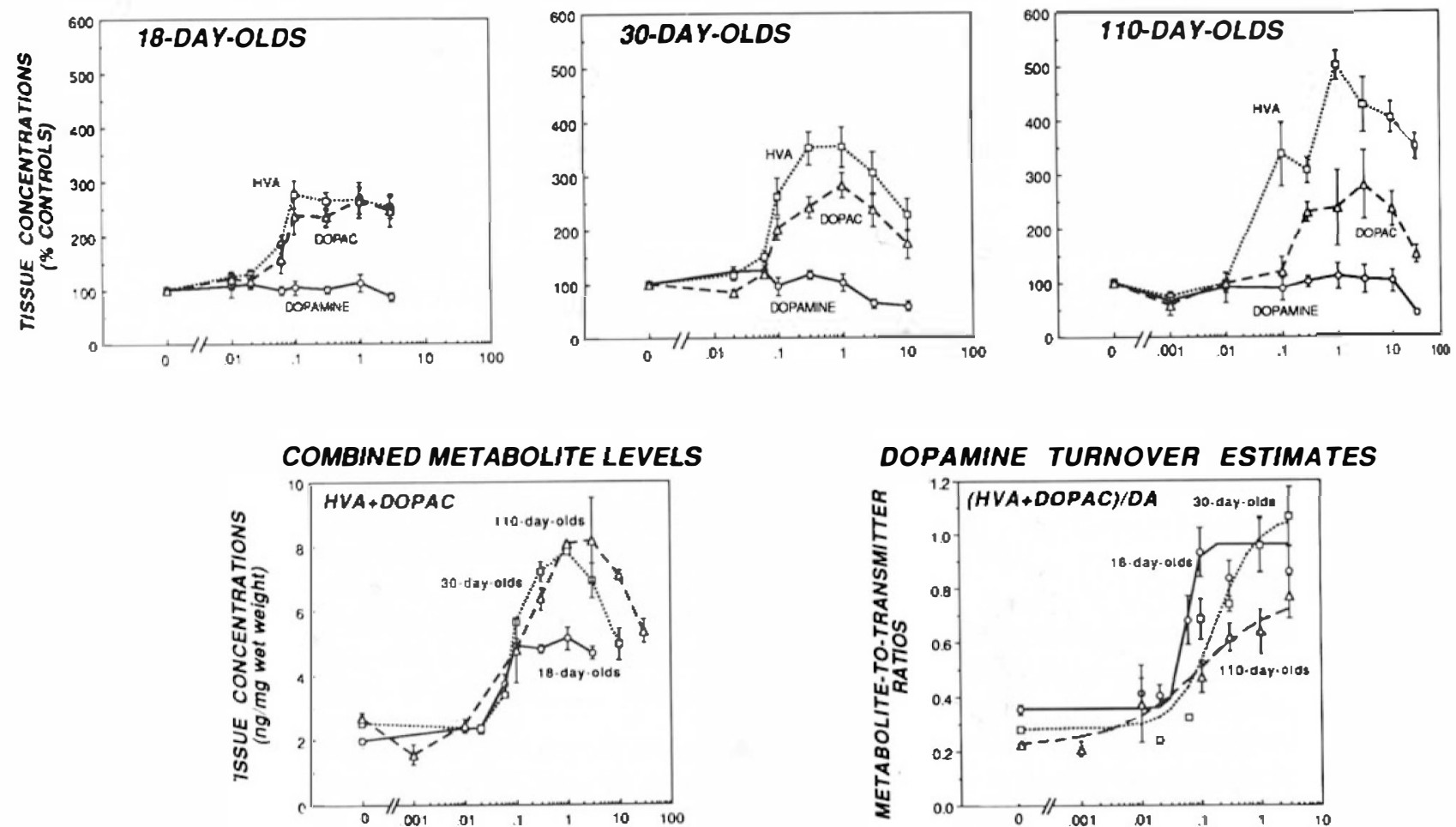

Figure 1. Dose-response curves in the corpus striatum. The top three panels show striatal concentrations of HVA, DOPAC, and DA in response to increasing doses of haloperidol $(1 \mu \mathrm{g}$ to $30 \mathrm{mg} / \mathrm{kg}$ ) expressed as a percentage of controls in $18-, 30$-, and 110-day-old rats. The lower left panel shows combined striatal concentrations of HVA + DOPAC (ng/mg wet weight) in response to the same range of doses of haloperidol. The lower right panel shows estimated DA turnover (metabolite-totransmitter ratio) in response to increasing doses of haloperidol (to $3 \mathrm{mg} / \mathrm{kg}$ ), as fit by ALLFIT. 

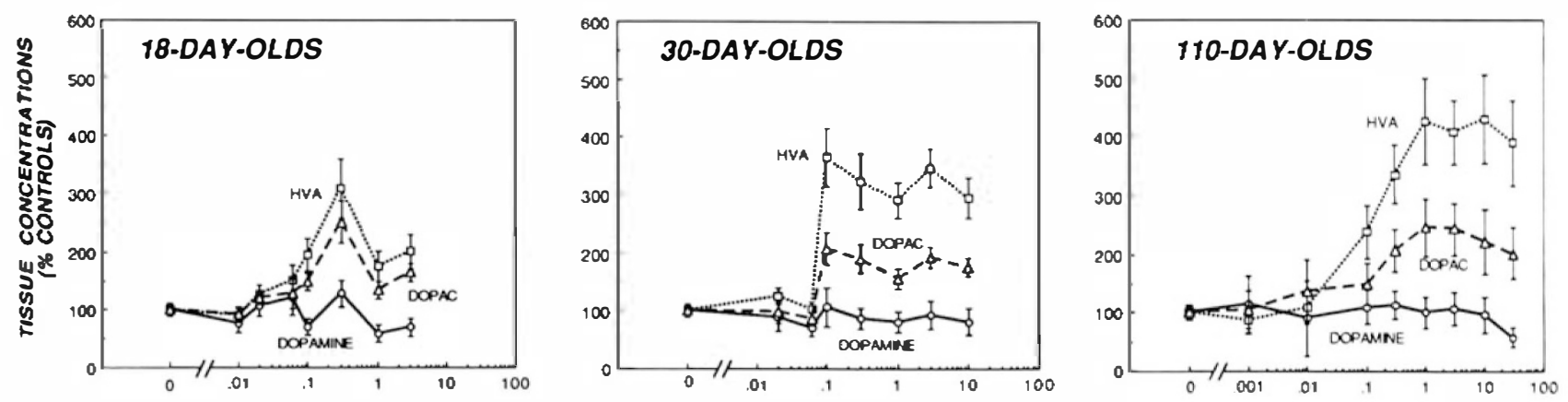

COMBINED METABOLITE LEVELS

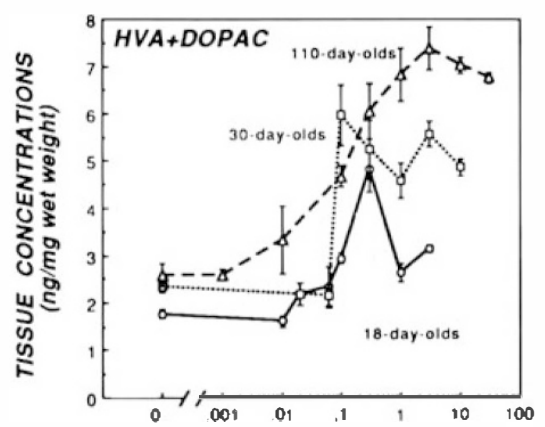

DOPAMINE TURNOVER ESTIMATES

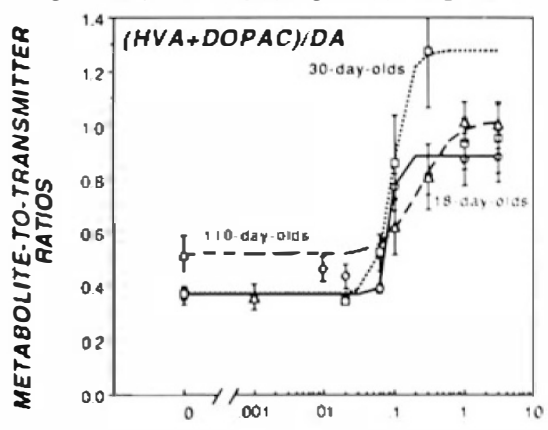

Figure 2. Dose-response curves in the nucleus accumbens. The top three panels show nucleus accumbens concentrations of HVA, DOPAC, and DA in response to increasing doses of haloperidol ( $1 \mu \mathrm{g}$ to $30 \mathrm{mg} / \mathrm{kg})$ expressed as a percentage of controls in 18-, 30-, and 110-day-old rats, as in Figure 1. The lower left panel shows combined accumbens concentrations of HVA + DOPAC (ng/mg wet weight) after doses of haloperidol. The lower right panel shows estimated DA turnover (metabolite-to-transmitter ratio) in response to increasing doses of haloperidol (to $3 \mathrm{mg} / \mathrm{kg}$ ), as fit by ALLFIT.

18 and 30 days were approximately $71 \% \pm 11 \%$ of adult levels. Overall, in this subcortical limbic region, the primary effect of age was a shift in the production of HVA andDOPAC, with 18-day-old rats producing relatively more HVA and less DOPAC. Metabolite-to-transmitter ratios increased slightly after 30 days of age.

Age Differences in Sensitivity to the Effects of Haloperidol on Mesolimbic DA System Response. There were prominent age differences in the $\mathrm{ED}_{50}$ of the metabolite-to-transmitter ratio $(F=15.1, p<.001)$. The $\mathrm{ED}_{50}$ was lowest at 18 days, nonsignificantly greater at 30 days, but substantially greater at 110 days $(171 \% \pm$ $26 \% ; p<.0001$; Table 3 ). The slope of the dose-response function also changed markedly with age. It was not possible to accurately determine the slope at 30 days, as HVA and DOPAC responses increased from basal levels at $0.06 \mathrm{mg} / \mathrm{kg}(160 \mathrm{nmol} / \mathrm{kg})$, to maximum levels at $0.10 \mathrm{mg} / \mathrm{kg}(266 \mathrm{nmol} / \mathrm{kg})$ of haloperidol. The dose-response function was less steep at 18 days and even less steep at 110 days (Fig. 2).

Overall, in the nucleus accumbens, 30-day-old rats were more sensitive (lower $\mathrm{ED}_{50}$ and $\mathrm{ED}_{\max }$ ) to the effects of haloperidol, as indicted by accumulation of HVA or DOPAC, and also displayed a very steep, virtually quantal, dose-response function, suggesting less efficient modulation and regulation at that age. Sensitivity of the metabolite responses was similar at 18 and 110 days of age, although the youngest rats were more sensitive to the effects of haloperidol on metabolite-totransmitter ratios and had steeper dose-response functions than the adults.

\section{Frontal Cortex}

Developmental Differences in Basal Metabolite Concentrations and Metabolite-to-Transmitter Ratios. There were no significant differences between ages in basal cortical levels of DA. Levels of HVA were $64 \% \pm 24 \%$ greater at 18 days $(p<.01)$, and $52 \% \pm 19 \%$ greater at 30 days $(p<.01)$ than in adults (Table 4$)$. Levels of DOPAC also varied across age, but in the opposite direction. Levels at 18 days were only $45 \% \pm 24 \%$ of adult levels $(p<.05)$. Turnover rates, based on combined metabolite-to-transmitter ratios, were marginally 
Table 3. Dopamine Metabolite Response to Haloperidol in Nucleus Accumbens

\begin{tabular}{|c|c|c|c|c|c|c|c|}
\hline Measure & $\begin{array}{c}\text { Age } \\
\text { (days) }\end{array}$ & $\begin{array}{l}\text { Basal Level } \\
\text { (ng/mg) }\end{array}$ & $\begin{array}{c}\text { Dose-Response } \\
\text { Slope }\end{array}$ & $\begin{array}{c}\text { Drug Potency } \\
\text { ED }_{50}\end{array}$ & $\begin{array}{c}\text { Maximal } \\
\text { Level } \\
\text { (ng/mg) }\end{array}$ & $\begin{array}{l}\text { Maximum \% } \\
\text { Change }\end{array}$ & $\begin{array}{c}\text { Maximally } \\
\text { Effective } \\
\left.\text { Dose (ED }{ }_{\max }\right)\end{array}$ \\
\hline DA & $\begin{array}{r}18 \\
30 \\
110\end{array}$ & $\begin{array}{l}4.832 \pm 0.546 \\
6.321 \pm 0.718 \\
6.306 \pm 0.863\end{array}$ & & & & & \\
\hline HVA & $\begin{array}{r}18 \\
30 \\
110\end{array}$ & $\begin{array}{l}0.718 \pm 0.062 \\
0.639 \pm 0.033 \\
0.673 \pm 0.055\end{array}$ & $\begin{array}{c}2.41 \pm 0.66 \\
>10 \text { lest. } \\
1.32 \pm 0.17\end{array}$ & $\begin{array}{l}0.101 \pm 0.011 \\
0.078 \pm 0.012 \\
0.135 \pm 0.013\end{array}$ & $\begin{array}{l}2.22 \pm 0.29 \\
2.34 \pm 0.24 \\
2.90 \pm 0.11\end{array}$ & $\begin{array}{l}309.7 \pm 51.4 \\
365.9 \pm 50.6 \\
431.1 \pm 74.3\end{array}$ & $\begin{array}{c}0.3 \\
0.1 \\
1.0-10.0\end{array}$ \\
\hline DOPAC & $\begin{array}{r}18 \\
30 \\
110\end{array}$ & $\begin{array}{l}1.037 \pm 0.059 \\
1.752 \pm 0.072 \\
1.906 \pm 0.197\end{array}$ & $\begin{array}{c}2.82 \pm 0.94 \\
>10 \text { (est.\} } \\
1.00 \pm 0.32\end{array}$ & $\begin{array}{l}0.120 \pm 0.016 \\
0.082 \pm 0.010 \\
0.122 \pm 0.039\end{array}$ & $\begin{array}{l}2.61 \pm 0.34 \\
3.63 \pm 0.41 \\
4.70 \pm 0.22\end{array}$ & $\begin{array}{l}251.8 \pm 36.7 \\
207.3 \pm 27.7 \\
246.3 \pm 48.2\end{array}$ & $\begin{array}{c}0.1-0.3 \\
0.1 \\
1.0\end{array}$ \\
\hline $\begin{array}{l}\text { DOPAC } \\
+ \text { HVA }\end{array}$ & $\begin{array}{r}18 \\
30 \\
110\end{array}$ & $\begin{array}{l}1.769 \pm 0.088 \\
2.536 \pm 0.155 \\
2.581 \pm 0.247\end{array}$ & $\begin{array}{l}2.71 \pm 0.87 \\
>10 \text { 'est.\} } \\
0.91 \pm 0.10\end{array}$ & $\begin{array}{l}0.112 \pm 0.014 \\
0.080 \pm 0.012 \\
0.111 \pm 0.014\end{array}$ & $\begin{array}{l}4.83 \pm 0.49 \\
5.97 \pm 0.65 \\
7.38 \pm 0.45\end{array}$ & $\begin{array}{l}273.2 \pm 31.5 \\
253.1 \pm 41.86 \\
285.8 \pm 46.2\end{array}$ & $\begin{array}{l}0.3 \\
0.1 \\
3.0\end{array}$ \\
\hline $\begin{array}{l}(\mathrm{DOPAC} \\
\quad+\mathrm{HVA}) / \mathrm{DA}\end{array}$ & $\begin{array}{r}18 \\
30 \\
110\end{array}$ & $\begin{array}{l}0.367 \pm 0.034 \\
0.372 \pm 0.024 \\
0.519 \pm 0.068\end{array}$ & $\begin{array}{l}8.25 \pm 4.73 \\
4.56 \pm 1.08 \\
1.83 \pm 0.28\end{array}$ & $\begin{array}{l}0.086 \pm 0.009 \\
0.077 \pm 0.005 \\
0.232 \pm 0.020\end{array}$ & $\begin{array}{l}0.884 \pm 0.096 \\
1.008 \pm 0.141 \\
1.013 \pm 0.075\end{array}$ & $\begin{array}{l}240.7 \pm 42.1 \\
271.3 \pm 45.3 \\
195.2 \pm 45.4\end{array}$ & $\begin{array}{c}3.0 \\
0.3 \\
1.0-3.0\end{array}$ \\
\hline
\end{tabular}

greater at younger ages. The most substantial developmental differences occurred in the basal ratio of HVA to DOPAC $(F=21.7, p<.0001)$. At 18 days, HVA levels were $2.9 \pm 0.2$ times greater than DOPAC levels. At 30 days, HV A levels exceeded DOPAC levels by 1.9\pm 0.2 -fold (18 versus 30 days: $p<.005$ ), but HVA levels only exceeded DOPAC levels by $1.4- \pm 0.1$-fold at 110 days (18 versus 110: $p<.05$ ).

Age Differences in Sensitivity to the Effects of Haloperidol. There were marked developmental differences in sensitivity of the cortex to the effects of this agent. The dose $\left(E D_{50}\right)$ of haloperidol required to produce a half-maximal rise in HVA $(F=23.4, p<.0001)$ and DOPAC $(F=31.6, p<.0001)$ varied substantially across age. Both 18- and 30-day-old animals were many fold more sensitive to the effects of haloperidol than were 110-day-olds. Curiously, there was no significant age difference in sensitivity to the effects of haloperidol on combined metabolite-to-transmitter ratios (Fig. 3).

\section{Regional Differences Within Each Age}

Basal Levels. Levels of DA, HVA, and DOPAC were very much lower in the PFCTX than in striatum or accumbens at each age. At 18 days, there were no significant differences between striatum and accumbens in levels of DA or DOPAC, but HVA levels were slightly greater in the striatum $(p<.02)$. At 30 days, striatal levels of DA and HVA exceeded accumbenslevels by $33 \%$

Table 4. Dopamine Metabolite Response to Haloperidol in PFCTX

\begin{tabular}{|c|c|c|c|c|c|c|c|}
\hline Measure & $\begin{array}{c}\text { Age } \\
\text { (days) }\end{array}$ & $\begin{array}{c}\text { Basal Level } \\
\text { (ng/mg) }\end{array}$ & $\begin{array}{c}\text { Dose-Response } \\
\text { Slope }\end{array}$ & $\begin{array}{c}\text { Drug Potency } \\
\text { ED }_{50}\end{array}$ & $\begin{array}{c}\text { Maximal } \\
\text { Level } \\
(\mathbf{n g} / \mathbf{m g})\end{array}$ & $\begin{array}{c}\text { Maximum \% } \\
\text { Change }\end{array}$ & $\begin{array}{c}\text { Maximally } \\
\text { Effective } \\
\text { Dose }\left(E D_{\max }\right)\end{array}$ \\
\hline DA & $\begin{array}{r}18 \\
30 \\
110\end{array}$ & $\begin{array}{l}0.101 \pm 0.022 \\
0.099 \pm 0.012 \\
0.106 \pm 0.013\end{array}$ & & & & & \\
\hline HVA & $\begin{array}{r}18 \\
30 \\
110\end{array}$ & $\begin{array}{l}0.091 \pm 0.011 \\
0.084 \pm 0.008 \\
0.055 \pm 0.005\end{array}$ & $\begin{array}{l}1.37 \pm 0.33 \\
1.92 \pm 0.37 \\
0.94 \pm 0.26\end{array}$ & $\begin{array}{l}0.033 \pm 0.009 \\
0.010 \pm 0.000 \\
0.398 \pm 0.146\end{array}$ & $\begin{array}{l}0.248 \pm 0.004 \\
0.232 \pm 0.056 \\
0.144 \pm 0.004\end{array}$ & $\begin{array}{l}273.7 \pm 66.7 \\
277.1 \pm 73.1 \\
260.0 \pm 31.1\end{array}$ & $\begin{array}{l}1.0 \\
0.1 \\
3.0\end{array}$ \\
\hline DOPAC & $\begin{array}{r}18 \\
30 \\
110\end{array}$ & $\begin{array}{l}0.029 \pm 0.004 \\
0.040 \pm 0.001 \\
0.043 \pm 0.004\end{array}$ & $\begin{array}{l}1.20 \pm 0.26 \\
0.40 \pm 0.18 \\
1.01 \pm 0.46\end{array}$ & $\begin{array}{l}0.017 \pm 0.003 \\
0.047 \pm 0.052 \\
1.887 \pm 0.767\end{array}$ & $\begin{array}{l}0.054 \pm 0.001 \\
0.086 \pm 0.018 \\
0.102 \pm 0.026\end{array}$ & $\begin{array}{l}182.7 \pm 37.4 \\
217.9 \pm 44.8 \\
239.4 \pm 67.4\end{array}$ & $\begin{array}{r}1.0 \\
3.0 \\
10.0\end{array}$ \\
\hline $\begin{array}{l}\text { DOPAC } \\
\quad+\text { HVA }\end{array}$ & $\begin{array}{r}18 \\
30 \\
110\end{array}$ & $\begin{array}{l}0.120 \pm 0.015 \\
0.124 \pm 0.010 \\
0.099 \pm 0.010\end{array}$ & $\begin{array}{l}1.36 \pm 0.23 \\
1.64 \pm 0.42 \\
0.88 \pm 0.17\end{array}$ & $\begin{array}{l}0.029 \pm 0.006 \\
0.011 \pm 0.001 \\
0.529 \pm 0.144\end{array}$ & $\begin{array}{l}0.299 \pm 0.005 \\
0.306 \pm 0.061 \\
0.228 \pm 0.028\end{array}$ & $\begin{array}{l}249.4 \pm 60.3 \\
245.9 \pm 53.9 \\
230.1 \pm 44.2\end{array}$ & $\begin{array}{r}1.0 \\
0.1 \\
10.0\end{array}$ \\
\hline $\begin{array}{l}(\mathrm{DOPAC} \\
+\mathrm{HVA}) / \mathrm{DA}\end{array}$ & $\begin{array}{r}18 \\
30 \\
110\end{array}$ & $\begin{array}{l}1.040 \pm 0.172 \\
1.114 \pm 0.110 \\
0.699 \pm 0.069\end{array}$ & $\begin{array}{l}2.86 \pm 0.02 \\
0.27 \pm 0.19 \\
0.24 \pm 0.11\end{array}$ & $\begin{array}{l}0.018 \pm 0.000 \\
0.005 \pm 0.011 \\
0.006 \pm 0.011\end{array}$ & $\begin{array}{l}3.297 \pm 0.459 \\
3.074 \pm 0.490 \\
1.646 \pm 0.161\end{array}$ & $\begin{array}{l}317.1 \pm 86.4 \\
276.0 \pm 52.3 \\
235.5 \pm 38.3\end{array}$ & $\begin{array}{r}1.0 \\
3.0 \\
10.0\end{array}$ \\
\hline
\end{tabular}



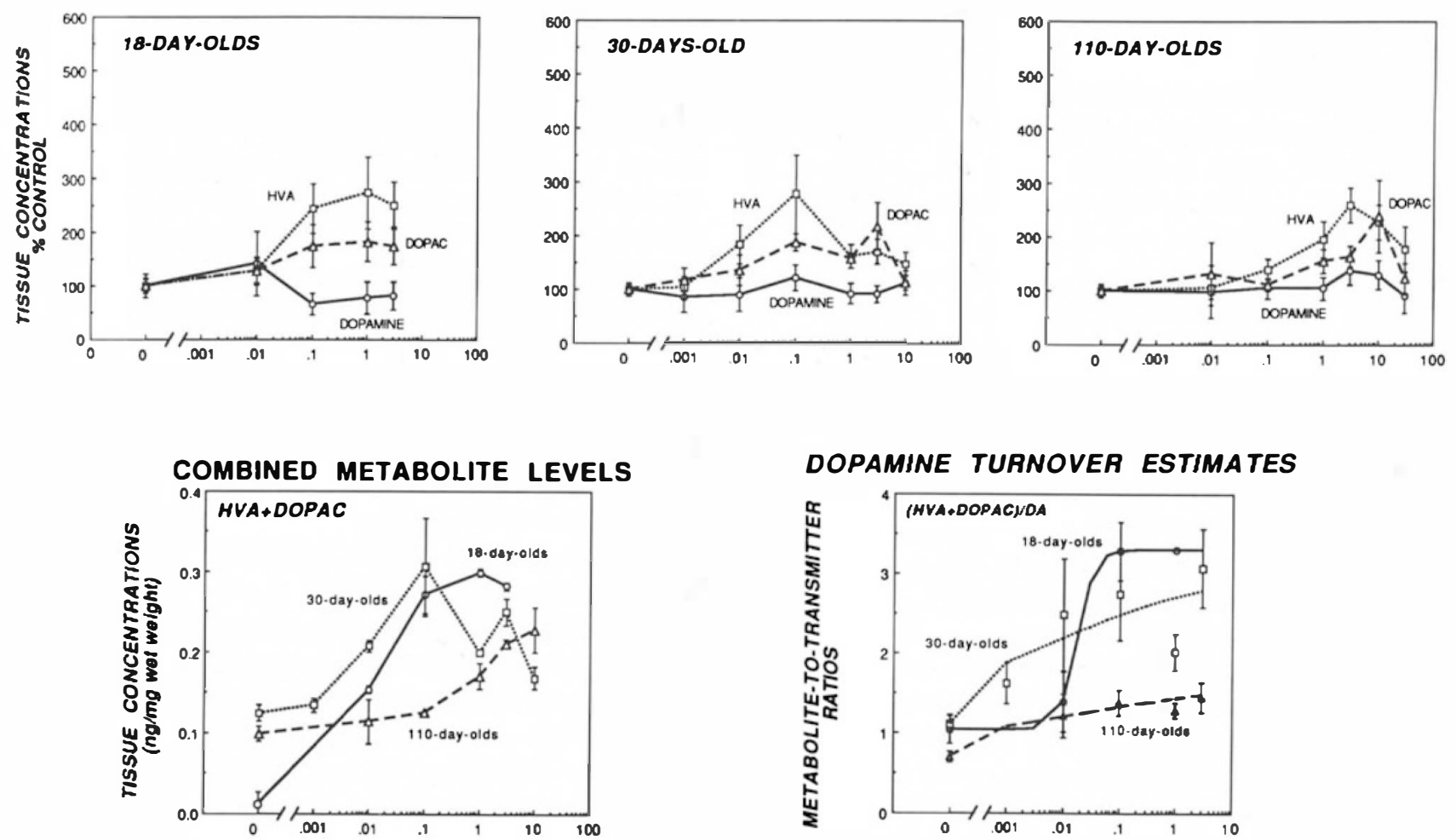

Figure 3. Dose-response curves in the prefrontal cortex. The top three panels show cortical concentrations of HVA, DOPAC, and DA in response to increasing doses of haloperidol $(1 \mu \mathrm{g}$ to $30 \mathrm{mg} / \mathrm{kg})$ expressed as a percentage of controls in 18-, 30-, and 110-day-old rats, as in Figures 1 and 2. The lower left panel shows combined cortical concentrations of HVA + DOPAC (ng/mg wet weight) in response to doses of haloperidol. The lower right panel shows estimated DA turnover (metabolite-totransmitter ratio) in response to increasing doses of haloperidol (to $3 \mathrm{mg} / \mathrm{kg}$ ), as fit by ALLFIT.

and $50 \%$ respectively $(p<.03)$. At 110 days, DA levels in striatum were $77.5 \% \pm 26.6 \%$ greater than in accumbens $(p<.00001)$ although there were no differences in metabolite levels between these regions. Thus, with maturation, there was a progressive increase in DA levelsin striatum relative to accumbens. As shown in Fig-

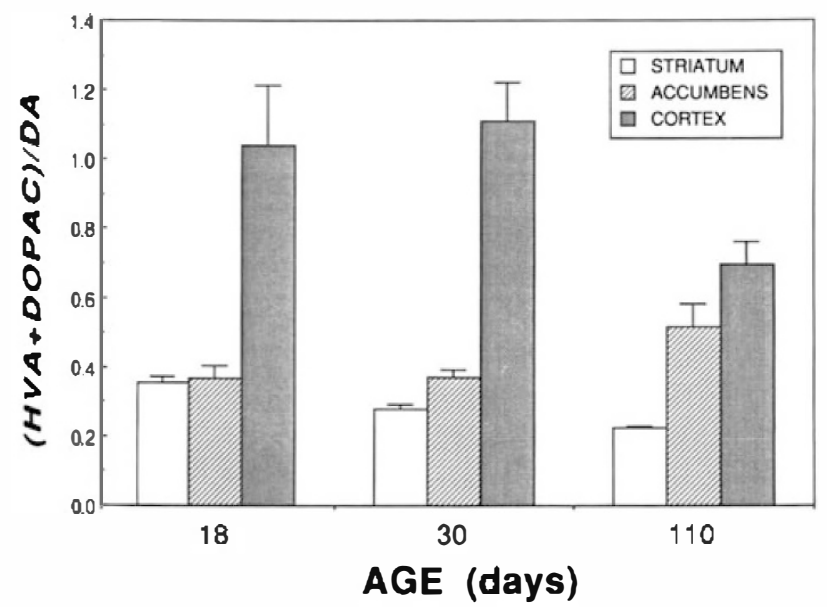

Fiqure 4. Basal turnover of DA (metabolite-to-transmitter ratio) in the corpus striatum, nucleus accumbens, and prefrontal cortex of 18-, 30-, and 110-day-old rats. ure 4, combined metabolite-to-transmitter ratios in striatum and accumbens were equivalent at 18 days, but $32.1 \% \pm 9.7 \%$ greater in accumbens at 30 days $(p<.002)$, and $131.7 \% \pm 30.9 \%$ greater at 110 days $(p<.0001)$. Hence, with maturation, there was a progressive increase in turnover rates in the accumbens relative to the striatum. At each age, estimated turnover rates in the PFCTX markedly exceeded those in the striatum by 1.9- to 3.0 -fold $(p<.00001)$. At 18 and 30 days, PFCTX turnover rates also greatly exceeded those in the accumbens (1.8- to 2 -fold; $p<.00001)$; however, at 110 days, metabolite-to-transmitter ratios in the PFCTX were not significantly greater than in the accumbens $(1.3- \pm 0.3-$ fold, $p>.13$ ). This lack of difference was due, in part, to a continued increase in accumbens turnover and a decrease in PFCTX turnover ratios (Fig. 4).

There were also relatively consistent differences between regions in the ratio of HVA to DOPAC. These ratios in PFCTX were 1.6- to 2.4-fold greater than those in the striatum at each age $(p<.00001)$. Striatal HVA to DOPAC ratios, in turn, exceeded those in the accumbens by $30 \%$ to $51 \%(p<.007)$ across age.

Sensitivity. There were dramatic differences between regions in sensitivity to haloperidol at each age. Of greatest importance may be the combined metabolite- 


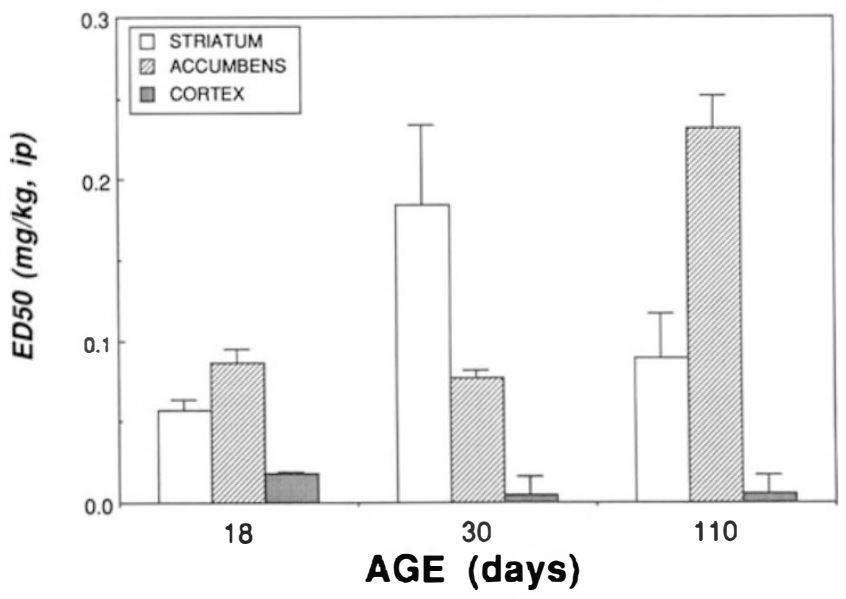

Figure 5. Potency of haloperidol in 18-, 30-, and 110-day old rats as measured by the dose $(\mathrm{mg} / \mathrm{kg})$ required to produce a half-maximal rise $\left(E D_{50}\right)$ in turnover ratio ([HVA + $\mathrm{DOPACJ} / \mathrm{DA}$ ) in the corpus striatum, nucleus accumbens, and PFCTX.

to-transmitter ratios ([HVA + DOPAC]/DA; Fig. 5). In 18-day-old animals, $\mathrm{ED}_{50}$ for this function was lowest in PFCTX, $218 \% \pm 40 \%$ greater in striatum $(p<.004)$, and $378 \% \pm 48 \%$ greater in accumbens $(p<.0001)$. At 30 days, the $\mathrm{ED}_{50}$ value for PFCTX was 15 times lower than in the accumbens $(p<.00001)$, and 36-fold lower than in striatum $(p<.01)$. At 110 days, the $\mathrm{ED}_{50}$ was also far lower in PFCTX than in the other regions and significantly greater in accumbens than striatum. In short, metabolite-to-transmitter ratios in the PFCTX were far more sensitive to haloperidol than in accumbens and striatum at each age tested. At 18 and 110 days, the striatum was $50 \%$ to $160 \%$ more sensitive than the accumbens, whereas at 30 days, the accumbens was $138 \%$ more sensitive than the striatum.

\section{DISCUSSION}

Prominent developmental differences were observed in the neurochemical response of forebrain DA systems to systemic haloperidol. The primary question we sought to answer was whether the immature DA system was more sensitive to the acute effects of haloperidol (lower $\mathrm{ED}_{50}$ ). In comparison to young adult rats, preweaning rats (18 days old) were $35 \%$ more sensitive to the effects of haloperidol on striatal turnover ([HVA + DOPAC]/DA) and $63 \%$ more sensitive to the effects of haloperidol on accumbens turnover. Thirtyday-old peripubertal rats were approximately $67 \%$ more sensitive to the effects of haloperidol on this estimate of DA turnover in the nucleus accumbens, but $106 \%$ less sensitive to the effects of haloperidol on turnover in the striatum. We compared these neuropharmaco- logic results to differences in behavioral sensitivity reported by Campbell and Baldessarini (1981) in rats of comparable age. A strong correlation emerged between sensitivity $\left(E_{50}\right)$ to the effects of haloperidol on striatal turnover and sensitivity to the effects of this agent on catalepsy $(r=0.969)$. There was no relationship between turnover sensitivity in the accumbens and sensitivity to catalepsy $(r=-0.082)$. Sensitivity to the sedative effects of haloperidol correlated more strongly with turnover sensitivity in the accumbens ( $r=0.694)$ than in striatum $(r=0.456)$ but correlated even more strongly with sensitivity in the PFCTX $(r=-0.934)$. Note however that this was a negative correlation, indicating that high sensitivity to haloperidol effects on turnover in the PFCTX was associated with low sensitivity to the sedative effects of haloperidol. Sensitivity to the locomotor activity-inhibiting effects of haloperidol was more strongly associated with turnover in the striatum $(r=0.887)$ than accumbens $(r=0.150)$, but was highly negatively associated with turnover in the PFCTX $(r=-0.968)$. Nevertheless, with assessment in only three ages, it is difficult to make much of these correlations other than to generate hypotheses. Our observations suggest that sensitivity to the cataleptic effects of haloperidol may be most directly related to turnover sensitivity in the striatum. Sensitivity to sedation may be directly related to sensitivity to haloperidol in the accumbens and inversely related to sensitivity in the PFCTX. Similarly, sensitivity to locomotor inhibition may be directly related to striatal sensitivity and inversely related to PFCTX sensitivity. Additional ages will need to be studied to evaluate these associations more adequately. These observations are consistent with studies that show that selectively depleting DA in PFCTX increases activity and arousal (Carter and Py. cock 1980; Bubser and Schmidt 1990), presumably through inhibitory pathways to striatum and accumbens. It is thus likely that the extremely high sensitivity of 18-day-old rats to the behavioral effects of haloperidol was a consequence of relatively high sensitivity in striatum and accumbens and possibly lower sensitivity in the PFCTX.

There were very prominent developmental differences in DA turnover response to haloperidol in the PFCTX. At 18 days, DA turnover in the PFCTX followed a typical sigmoidal dose-response function, similar to such curves in the accumbens and striatum. While 30 day-old and adult rats had prominent sigmoidal response curves in striatum and accumbens (Figs. 1 and 2), they had a nearly flat response in PFCTX (Fig. 3). The slope of the dose-response curve in PFCTX was 10 -fold greater at 18 days than at 30 or 110 days. Bannon et al. $(1982,1983)$ previously reported that the adult PFCTX displays relatively little compensatory change in activity following acute neuroleptic challenge and fails to develop tolerance to repeated neuroleptic treat- 
ment. They postulated that this was a consequence of the lack of presynaptic synthesis-modulating DA autoreceptor function. The more prominent sigmoidal response of the PFCTX in 18-day-old rats may be related to the recent observation of Teicher et al. (1991) that there appears to be a transient population of synthesismodulating $D_{1}$-like autoreceptor in the PFCTX of the developing rat. Dopamine $D_{1}$ receptor-mediated modulation of DA synthesis in the PFCTX was present from 15 to 22 days of age but faded thereafter. The present findings suggest that the PFCTX is not very different from striatum and accumbens in its response to haloperidol at 18 days, but develops a more unique response pattern with maturation.

Our findings also indicate that there were significant developmental differences in production of HVA and DOPAC. In all three major forebrain target regions, there was a progressive developmental decline in HVA levels and a progressive increase in DOPAC levels. Keller et al. (1973) have proposed that a large fraction of DOPAC results from leakage of DA from storage sites into cytosol and is thus strongly influenced by endogenous DA levels. Coyle and Molliver (1977) have also shown that the immature brain has a remarkable, albeit unused, capacity to store catecholamines. Thus, cytosolic leakage may also be affected by developmenal differences in DA storage capacity and levels. It is interesting that haloperidol produced a comparable percent rise in DOPAC levels at each age in all regions. In contrast, the percent rise in HVA levels in striatum and accumbens following maximally effective doses of haloperidol was progressively greater at 30 and 110 days. Released DA transported back into DA neurons is metabolized, largely, into DOPAC. Homovanillic acid predominantly derives from DA that is initially metabolized extraneuronally (Keller et al. 1973). Thus, our observations suggest that, in adult accumbens and striatum, maximally stimulated DA release can significantly outstrip reuptake capacity. In future studies it will be useful to measure 3-methoxytyramine, as a more direct indicator of DA release (Kehr 1976; Nissbrandt and Carlsson 1987) and to provide more comprehensive pharmacologic estimates of turnover and tyrosine hydroxylase activity (Nissbrandt and Carlsson 1987).

Although one must be very cautious in extrapolating findings from rats to man, it is reasonable to ponder whether the present findings have any clinical implications or correlates. First, it is apparent that there were significant changes is the neuropharmacologic properties of the PFCTX between the ages studied. Turnover response in the PFCTX was very different in preweaning prepubertal rats and peripubertal rats at 30 days. There were also marked differences between 30-day-old and adult rats in the degree of basal turnover of DA and the level of accumulation its metabolites. These age-dependent differences in pharmacologic properties of the PFCTX may have some relationship to the age of onset of schizophrenia. Childhood cases fulfilling adult criteria for schizophrenia are rare (Kydd and Werry 1982). The majority of cases emerge between 15 and 35 years of age (Babigian 1980). Weinberger (1987) has formulated an important neurodevelopmental theory, which proposes that a fixed lesion present in early life is ultimately responsible for schizophrenia. However, this lesion may be relatively silent during childhood until normal maturational events unfold, possibly in the PFCTX, which then enable the effect of the lesion to become more fully manifest. The present findings clearly show prominent differences between the ages studied in the pharmacologic response properties of the PFCTX. This may be due to the transient expression of PFCTX DA autoreceptor-like function (Teicher et al. 1991). By suppressing DA synthesis during periods of high neuronal activity, such a mechanism may normally help to protect against the expression of psychotic illness during the prepubertal period.

Our findings also indicate that prepubertal (18-dayold) rats were very sensitive to the effects of haloperidol on striatal DA turnover, and Campbell and Baldessarini (1981) have shown that animals at this age are exquisitely sensitive to cataleptic effects of neuroleptics. These observations may have some relationship to clinical observations that indicate that children may be at relatively high risk for developing neuroleptic malignant syndrome (NMS) during neuroleptic treatment. In children less than 6 years of age, almost all reported cases of NMS occurred after ingestion of only a single dose of neuroleptic (Latz and McCracken 1992). The fatality rate from NMS was $13 \%$ among adolescent patients with NMS $(n=38)$, and $33 \%$ in patients 12 years or younger $(n=11)$ (Latz and McCracken 1992).

Our findings also indicate that younger rats have substantially steeper dose-response curves than adults. Evidently, at younger ages, slight differences in dose around the $\mathrm{ED}_{50}$ can have substantial effects on turnover or metabolite accumulation. This was most clearly seen in the accumbens of 30-day-old rats. Accumulation of HVA and DOPAC were not affected by doses of haloperidolless than or equal to $60 \mu \mathrm{g} / \mathrm{kg}(160 \mathrm{nmol} / \mathrm{kg})$, but were increased maximally by doses of only 100 $\mu \mathrm{g} / \mathrm{kg}(266 \mathrm{nmol} / \mathrm{kg})$. Steep dose-response functions may make it difficult to adjust dose, and they indicate that it may be necessary to switch to a different drug to obtain a more favorable response profile. This phenomenon may have relevance to the thorny problem of effectively treating children with Tourette's disorder, without producing undue sedation. Both the high sensitivity of the accumbens in younger animals and its steep dose-response functions at that age may make it difficult to find a dose of haloperidol that inhibits motor tics without interfering excessively with arousal. In some cases, switching to a different agent may be more 
successful than attempting to titrate dose (Teicher and Glod 1990).

Overall, the present study adds to our knowledge about important developmental differences in neurochemical response to antipsychotic drugs. Further research is in progress to evaluate dose-dependent effects on transmitter release and postsynaptic receptor response to classic antipsychotic drugs and to more selective DA receptor antagonists.

\section{ACKNOWLEDGMENTS}

This research was supported, in part, by National Institute of Mental Health Grants MH-43743, MH-31154, MH-34006, and $\mathrm{MH}-47370$ and by donations from the Bruce J. Anderson Foundation and the Marion Ireland Benton Foundation. We thank McNeil Labs for their generous donation of haloperidol.

\section{REFERENCES}

Babigian HM (1980): Schizophrenia: Epidemiology. In Kaplan HI, Freedman AM, Sadock BJ (eds), Comprehensive Textbook of Psychiatry/III. Baltimore, Williams \& Wilkins, pp 1115-1117

Baldessarini RJ (1985): Chemotherapy in Psychiatry. Cambridge MA, Harvard University Press

Baldessarini RJ, Cohen BM, Teicher MH (1988): Significance of neuroleptic dose and plasma level in the pharmacological treatment of psychoses. Arch Gen Psychiatry 45:79-91

Baldessarini RJ, Marsh ER, Kula NS, Zong R, Gao Y, Neumeyer JL (1990): Effects of isomers of hydroxyaporphines on dopamine metabolism in rat brain regions. Biochem Pharmacol 40:417-423

Bannon MJ, Reinhard JR Jr, Bunney EB, Roth RH (1982): Unique response to antipsychotic drugs is due to absence of terminal autoreceptors in mesocortical dopamine neurons. Nature 296:444-446

Bannon MJ, Wolf MA, Roth RH(1983): Pharmacology of dopamine neurons innervating the prefrontal, cingulate, and piriform corticies. Eur J Pharmacol 91:119-125

Bubser M, Schmidt WJ (1990): 6-Hydroxydopamine lesion of the rat prefrontal cortex increases locomotor activity, impairs acquisition of delayed alternation tasks, but does not affect uninterrupted tasks in the radial maze. Behav Brain Res 37:157-168

Campbell A, Baldessarini RJ (1982): Circadian changes in behavioral effects of haloperidol in rats. Psychopharmacology 77:150-155

Campbell A, Baldessarini RJ (1981): Effects of maturation and aging on behavioral response to haloperidol in the rat. Psychopharmacology 73:219-222
Campbell A, Baldessarini RJ, Teicher MH (1988): Decreasing sensitivity to neuroleptic agents in developing rats: Evidence for a pharmacodynamic factor. Psychopharmacology $94: 46-51$

Carter CJ, Pycock CJ (1980): Behavioral and biochemical effects of dopamine and nor-adrenaline depletion within the medial prefrontal cortex of the rat. Brain Res 192:163-176

Coyle JT, Molliver ME (1977): Major innervation of newborm rat cortex by monoaminergic neurons. Science 196:444447

DeLean A, Munson PG, Rodbard D (1978): Simultaneous analysis of families of sigmoid curves: Application to bioassay, radioligand assay, and physiological dose-response curves. Am J Physiol 235:E97-E102

Kehr W (1976): 3-Methoxytyramine as an indicator of impulseinduced dopamine release in the rat brain in vivo. Naunyn Schmiedbergs Arch Pharmacol 293:209-215

Keller HH, Bartholini G, Pletscher A (1973): Spontaneous and drug-induced changes of cerebral dopamine turnover during postnatal development of rats. Brain Res 64: 371-378

Keppel G (1973): Design and Analysis: A Researcher's Handbook. Englewood Cliffs NJ, Prentice-Hall, pp 355-360

Kydd RR, Werry JS (1982): Schizophrenia in children under 16 years. J Autism Dev Dis 12:343-356

Latz SR, McCracken JT (1992): Neuroleptic malignant syndrome in children and adolescents: Two case reports and a warning. J Child Adol Psychopharmacol 2:123-129

McLean RA, Welsch BL (1971): A common error in assessing the significance of percentage change in neuropharmacology. J Pharm Pharmacol 23:643-645

Nissbrandt H, Carlsson A (1987): Turnover of dopamine and dopamine metabolites in rat brain: Comparison between striatum and substantia nigra. J Neurochem 49:959-967

Seeman P, Bzowij NH, Guan HC, Bergeron C, Becker LE, Reynolds GP, Bird ED, Riederer $P$, Jellinger $K$, Wanatabe $S$ (1987): Human brain dopamine receptors in children and aging adults. Synapse 1:399-404

Teicher MH, Barber NI, Reichheld J, Baldessarini RJ (1986): Selective depletion of cerebral norepinephrine with 6-hydroxydopamine and GBR-12909 in rats. Dev Brain Res 30:124-128

Teicher MH, Gallitano AL, Gelbard HA, Evans HK, Marsh ER, Booth RG, Baldessarini RJ (1991): Dopamine $D_{1}$ autoreceptor function: Possible expression in developing rat prefrontal cortex and striatum. Dev Brain Res 61:229-235

Teicher MH, Glod CA (1990): Neuroleptic drugs: Indications and guidelines for their rational use in children and adolescents. J Child Adol Psychopharmacol 1:33-56

Weinberger DR (1987): Implications of normal brain development for the pathogenesis of schizophrenia. Arch Gen Psychiatry 44:660-669 